\title{
Influence of genetic factors on the fertilization of mouse ova in vitro
}

\author{
Elżbieta Kaleta \\ Department of Genetics and Evolution, Institute of Zoology, Jagellonian University, Krupnicza 50, \\ 30-060 Kraków, Poland
}

\begin{abstract}
Summary. In-vitro fertilization was studied in $F_{1}$ hybrids, 4 inbred and outbred strains of mice. Experiments were performed with intact ova (Series I) and denuded ova (Series II). In Series I the highest percentages of fertilization were obtained with gametes of $F_{1}$ hybrids $(86.7 \%$ ) and of the CBA strain $(87.5 \%)$. The KP, KE, and particularly the $\mathrm{C} 57$ strains, which in vivo give less than $100 \%$ fertilization, also gave low indices in vitro $(42 \cdot 9,26.0$ and $8.6 \%$ respectively). Testing gametes of these inbred strains with $F_{1}$ gametes showed that spermatozoa and ova are responsible for the low percentages of fertilization. The rate of fertilization was mainly dependent on the genotype of the spermatozoon. In Series II, high percentages of fertilization (97-100\%) were regularly obtained in all groups, indicating that differences between strains pertained mainly to binding of spermatozoa with the zona pellucida. The incidence of polyspermy, which did not exceed $5 \%$ in Series I and reached $58 \%$ in Series II, was dependent on the genotype of both gametes.
\end{abstract}

\section{Introduction}

Inbred strains of mice show different indices of fertilization in vivo, e.g. the percentage and rate of fertilization, occurrence of polyspermy and penetration of supplementary spermatozoa (Braden, 1958; Krzanowska, 1960, 1970; McLaren \& Bowman, 1973). These differences indicate that genetic factors play a significant role in the functioning of gametes. Under natural conditions, however, analysis is complicated by a number of additional factors: disturbances of synchronization between ovulation and copulation may result in sterile copulations or in a lower percentage of fertilization (Krzanowska, 1960; Kaleta, Antos \& Nowicka, 1976) and the environment of the female tract may affect the transport of spermatozoa (Nicol \& McLaren, 1974), the viability of the gametes and their interaction.

These complications can be avoided by using fertilization in vitro in medium of known composition. This method has been successfully used for several years, but most experiments have been carried out with highly viable gametes from $F_{1}$ hybrids or outbred mice which give high percentages of fertilization in vitro. There is little information about differences between inbred strains of mice (Iwamatsu \& Chang, 1971; Pavlok, 1971), which generally show lower indices of fertilization in vitro.

Because mouse inbred strains with known parameters of fertility were available, the present study, comparing the effectiveness of fertilization in vivo and in vitro under various experimental conditions, was an analysis of the malfunctions of spermatozoa and ova which result in a reduction of the percentage and rate of fertilization in some inbred strains.

\section{Materials and Methods}

The mice used were 2-4 months old and from the inbred strains KP, KE (Krzanowska, 1965), CBA/Kw and C57BL/Kw (referred to hereafter as CBA and C57, respectively), their $\mathrm{F}_{1}$ hybrids, and from an outbred stock. When describing $F_{1}$ hybrids, the strain of the female is given first.

Superovulation in females was induced by injecting 8-10 i.u. PMSG and, 48-50 h later, 8-10 i.u. 
HCG. Ova were removed from the oviducts $14-18 \mathrm{~h}$ after the HCG injection. Fertilization in vitro was performed in two series. In the first series, intact ova, as isolated from the oviducts, were used, and in the second, the ova were denuded enzymatically of cumulus cells and zona pellucida. As it was impossible to test all genetic groups in every experiment, fertilization of gametes from the inbred strains was performed in parallel with fertilization of the $F_{1}$ hybrid gametes which served as a control. If fertilization of the $F_{1}$ gametes dropped below $60 \%$, the results of this experiment were discarded.

\section{Series I}

Ova were placed into a drop (about $0.4 \mathrm{ml}$ ) of culture medium prepared as described by Toyoda, Yokoyama \& Hosi (1971), but freeze-dried bovine serum albumin (Fraction V) inactivated for $90 \mathrm{~min}$ at $56-57^{\circ} \mathrm{C}$ was used instead of crystalline albumin. The number of ova per drop ranged from 10 to 30 . Spermatozoa were expressed from the vasa deferentia of male mice to another drop of culture medium (about $0.4 \mathrm{ml}$ ), after gentle pressure of the cauda epididymidis. The spermatozoa were allowed to disperse for $10-15 \mathrm{~min}$ at $37^{\circ} \mathrm{C}$. After thorough mixing, about $0.02 \mathrm{ml}$ sperm suspension was transferred to the drop containing ova, giving a final concentration of 100-600 spermatozoa $/ \mathrm{ml}$. After incubation at $37.5^{\circ} \mathrm{C}$ for $7 \mathrm{~h}$ in an atmosphere of $5 \% \mathrm{CO}_{2}$ in air, the ova were washed with $0.9 \% \mathrm{NaCl}$ and inspected under the microscope, fresh and then after fixation in absolute alcohol : glacial acetic acid $(3: 1 \mathrm{v} / \mathrm{v})$.

Ova at metaphase of the second meiotic division, with chromosomes arranged in the equatorial plane of the spindle, were classified as unfertilized, regardless of the possible presence of spermatozoa under the zona pellucida. In fertilized ova, three stages were distinguished: (1) those at anaphase and containing a sperm head in the cytoplasm; (2) those with the second polar body and a sperm head in the cytoplasm; and (3) those with the second polar body and two or more pronuclei. Ova identified as old, i.e. with a distinctly detached zona pellucida and scattered chromosomes, or as activated, i.e. with the second polar body and only one pronucleus, were excluded from analysis.

In experiments in which the numbers of supplementary spermatozoa were estimated, ova were incubated for 8-9 h. By this time nearly all fertilized ova had formed pronuclei which were visible without fixation (during which the zona pellucida dissolves), and the presence of supplementary spermatozoa in the perivitelline space could easily be detected in fertilized or unfertilized ova.

\section{Series II}

Ova were isolated in a drop of culture medium of $\mathrm{pH} \mathrm{7.6} \mathrm{(without} \mathrm{bovine} \mathrm{serum} \mathrm{albumin),} \mathrm{con-}$ taining testicular hyaluronidase $(0.025 \%)$. The cumulus cells dispersed within $10 \mathrm{~min}$, and old ova which had fragmented or had a detached zona pellucida were removed. The ova were then washed in culture fluid and transferred to the culture fluid containing $\alpha$-chymotrypsin $(9000$ ATEE units/mg: Koch-Light) at a concentration of $0.003 \%$. Depending on the genotype, the time required to dissolve the zona pellucida varied, but prolonged treatment with enzyme solution considerably reduced the percentage of fertilized ova. The zona pellucida was therefore removed mechanically from ova of the C57 and KE strains after incubation with $\alpha$-chymotrypsin for $15 \mathrm{~min}$. After two washings in culture fluid, denuded ova were incubated under the same conditions as in Series I, except that the concentrations of spermatozoa were reduced by $50 \%$.

Statistical differences were determined by a $2 \times 2$ or $\mathrm{R} \times 2$ test of independence (Snedecor, 1955).

\section{Results}

\section{Series $I: \%$ and rate of fertilization of intact ova in vitro}

The results obtained (Table 1) show that the effectiveness of fertilization was clearly dependent on the genotype. Gametes of $F_{1}$ hybrids showed high percentages of fertilized ova and fertilization rates, and relatively low coefficients of variation. There were no significant differences according to the cross and the results for reciprocal hybrids were therefore combined. The highest percentage of 
Table 1. Percentage and rate of fertilization in vitro of ova surrounded by the zona pellucida and cumulus cells

\begin{tabular}{|c|c|c|c|c|c|c|c|c|}
\hline \multirow{2}{*}{\multicolumn{2}{|c|}{ Genotype }} & \multirow{3}{*}{$\begin{array}{l}\text { No. of } \\
\text { eggs } \\
\text { tested } \\
\text { (no. of } \\
\text { exps) }\end{array}$} & \multicolumn{3}{|c|}{ No. of fertilized ova: } & \multirow{3}{*}{$\begin{array}{c}\text { Fertilized } \\
\text { ova } \\
(\%)\end{array}$} & \multirow{3}{*}{$\begin{array}{c}\text { Ova with } \\
\text { pronuclei/ } \\
\text { no. fertilized } \\
(\%)\end{array}$} & \multirow{3}{*}{$\begin{array}{l}\text { Poly- } \\
\text { spermic } \\
\text { eggs } \\
(\%)\end{array}$} \\
\hline & & & \multirow{2}{*}{$\begin{array}{c}\text { At } \\
\text { ana- } \\
\text { phase }\end{array}$} & \multirow{2}{*}{$\begin{array}{l}\text { With } \\
\text { 2nd } \\
\text { polar } \\
\text { body }\end{array}$} & \multirow{2}{*}{$\begin{array}{c}\text { With } \\
\text { pro- } \\
\text { nuclei }\end{array}$} & & & \\
\hline Ova & Spermatozoa & & & & & & & \\
\hline $\begin{array}{l}F_{1}(\mathrm{KE} \times \mathrm{CBA}) \\
\mathrm{F}_{1}(\mathrm{CBA} \times \mathrm{KE})\end{array}$ & $\left.\begin{array}{l}\mathrm{F}_{1}(\mathrm{KE} \times \mathrm{CBA}) \\
\mathrm{F}_{1}(\mathrm{CBA} \times \mathrm{KE})\end{array}\right\}$ & $438(22)$ & 1 & 64 & 315 & $86 \cdot 7$ & $82 \cdot 8$ & $2 \cdot 3$ \\
\hline $\begin{array}{l}F_{1}(\mathrm{CBA} \times \mathrm{C} 57) \\
\mathrm{F}_{1}(\mathrm{C} 57 \times \mathrm{CBA})\end{array}$ & $\left.\begin{array}{l}F_{1}(\mathrm{CBA} \times \mathrm{C} 57) \\
\mathrm{F}_{1}(\mathrm{C} 57 \times \mathrm{CBA})\end{array}\right\}$ & $298(22)$ & 4 & 85 & 142 & $77 \cdot 5$ & $61 \cdot 5$ & $1 \cdot 3$ \\
\hline$F_{1}(\mathrm{C} 57 \times \mathrm{KE})$ & $\mathrm{F}_{1}(\mathrm{C} 57 \times \mathrm{KE})$ & $191(8)$ & 2 & 84 & 55 & $73 \cdot 8$ & $39 \cdot 0$ & - \\
\hline Outbred & $\mathrm{F}_{1}$ & $264(22)$ & 7 & 57 & 142 & $78 \cdot 1$ & $68 \cdot 9$ & 1.9 \\
\hline CBA & $\mathrm{CBA}$ & $241(14)$ & 10 & 37 & 164 & $87 \cdot 5$ & $77 \cdot 7$ & $4 \cdot 3$ \\
\hline CBA & $F_{1}$ & $229(12)$ & 1 & 44 & 153 & $86 \cdot 5$ & $77 \cdot 3$ & 3.0 \\
\hline$F_{1}$ & CBA & $228(13)$ & 2 & 21 & 181 & $89 \cdot 5$ & $88 \cdot 7^{* *}$ & 3.9 \\
\hline Outbred & $\mathrm{CBA}$ & $297(14)$ & 1 & 27 & 229 & $86 \cdot 5$ & $89 \cdot 1^{* *}$ & 0.7 \\
\hline KP & KP & $256(10)$ & 1 & 54 & 55 & $42 \cdot 9$ & $50 \cdot 0$ & - \\
\hline $\mathrm{KP}$ & $F_{1}$ & $249(13)$ & 3 & 29 & 111 & $57 \cdot 4^{* *}$ & $77 \cdot 6 * *$ & 0.7 \\
\hline$F_{1}$ & KP & $314(15)$ & 3 & 6 & 23 & $10 \cdot 1^{* *}$ & $71 \cdot 8^{* * *}$ & - \\
\hline Outbred & $\mathrm{KP}$ & $231(13)$ & 5 & 17 & 16 & $16 \cdot 4^{* *}$ & $42 \cdot 1$ & - \\
\hline KE & $\mathrm{KE}$ & $200(15)$ & 2 & 11 & 39 & $26 \cdot 0$ & $75 \cdot 0$ & 1.9 \\
\hline $\mathrm{KE}$ & $F_{1}$ & $151(13)$ & 1 & 9 & 34 & $29 \cdot 1$ & $77 \cdot 3$ & $2 \cdot 2$ \\
\hline$F_{1}$ & $\mathrm{KE}$ & 304 (17) & 2 & 31 & 131 & $53 \cdot 9 * *$ & $79 \cdot 8$ & - \\
\hline Outbred & KE & $228(15)$ & 3 & 19 & 47 & $30 \cdot 3$ & $68 \cdot 1$ & $1 \cdot 4$ \\
\hline C57 & C57 & $231(23)$ & 1 & 9 & 10 & $8 \cdot 6$ & $50 \cdot 0$ & - \\
\hline $\mathrm{C} 57$ & $F_{1}$ & $197(17)$ & 2 & 9 & 43 & $27 \cdot 4^{* *}$ & $79 \cdot 6^{*}$ & 3.7 \\
\hline$F_{1}$ & C57 & 194 (13) & 5 & 24 & 13 & $21 \cdot 6^{* *}$ & 30.9 & $2 \cdot 4$ \\
\hline Outbred & $\mathrm{C} 57$ & $261(15)$ & 1 & 12 & 9 & $8 \cdot 4$ & $40 \cdot 9$ & - \\
\hline CBA & C57 & $319(14)$ & 9 & 23 & 15 & $14 \cdot 7$ & 31.9 & - \\
\hline C57 & $\mathrm{CBA}$ & 164 (14) & 1 & 12 & 43 & $34 \cdot 2$ & $76 \cdot 8$ & 1.8 \\
\hline
\end{tabular}

$F_{1}$ refers to $F_{1}$ hybrid gametes from the reciprocal crosses between CBA and C57 or CBA and KE strains - both groups being used in the same proportions for each testing.

Difference between the intrastrain value and that for the cross significant at ${ }^{* *} P<0.005 ;{ }^{*} P<0.05$.

fertilization was obtained with $F_{1}$ hybrids from crosses between the KE and CBA strains, while the other groups of $F_{1}$ hybrids gave significantly lower results $(P<0.005)$.

The CBA mice and their hybrids had high fertilization percentages and rates of fertilization. The other inbred strains gave significantly lower $(P<0.005)$ results, especially the C57 mice. In comparison with the $F_{1}$ hybrids and the inbred CBA mice, the inbred KP and C57 strains had the lowest rates of fertilization ( $50 \%$ of eggs with pronuclei).

To ascertain whether ova or spermatozoa were responsible for the low percentages of fertilization in vitro, gametes of the inbred strains were tested with gametes from $F_{1}$ hybrids, or from outbred females. The results for the CBA strain gave a percentage fertilization as high as that for the inbred or $F_{1}$ hybrid gametes. However, insemination of ova of KP, KE and C57 strains with $F_{1}$ spermatozoa and vice versa in most cases improved the percentages of fertilization indicating that the genotype of both gametes was a contributory factor. Comparison of the percentages of $F_{1}$ or outbred ova fertilized by spermatozoa from each of the four strains gave highly significant differences $(\mathrm{R} \times 2$; $P<0.005)$, confirming the influence of sperm genotype on fertilization. A similar analysis made with $F_{1}$ spermatozoa and ova of inbred and outbred strains showed that the effectiveness of fertilization also depended on the genotype of the ova $(P<0.005)$. 
The rate of fertilization was mainly dependent on the genotype of the spermatozoa. Spermatozoa of $F_{1}$ hybrids usually accelerated the rate of fertilization, especially of the KP and C57 ova. In all variants in which $\mathrm{C} 57$ spermatozoa were used, the percentage and rate of fertilization were reduced. This was particularly noticeable in an additional test in which fertilization of CBA ova with C57 spermatozoa gave significantly lower results than the opposite combination.

The percentages of polyspermic ova in relation to all fertilized ova were low and did not exceed $5 \%$.

Supplementary spermatozoa. When the ova of outbred females were inseminated with CBA spermatozoa (209 ova) supplementary spermatozoa (1-2/ovum) were found in $43.6 \%$ of fertilized ova and in $30.3 \%$ of unfertilized ova (difference not significant). When KE spermatozoa were used (306 ova), supplementary spermatozoa (1-5/ovum or more) were found in $69.8 \%$ of fertilized ova, and in only $26.2 \%$ of unfertilized ova $(P<0.005)$. Statistical analysis showed that KE spermatozoa penetrated the zona pellucida of fertilized outbred ova in a significantly higher percentage of cases compared with CBA spermatozoa $(P<0.005)$. In unfertilized ova, $\mathrm{KE}$ and CBA spermatozoa were noted in the perivitelline space in approximately similar proportions (not significant).

Table 2. Fertilization in vitro of eggs without a zona pellucida

\begin{tabular}{|c|c|c|c|c|c|c|c|c|}
\hline \multicolumn{6}{|c|}{ No. of fertilized eggs } & \multirow{3}{*}{$\begin{array}{l}\text { Fertilized } \\
\text { eggs }(\%)\end{array}$} & \multirow{3}{*}{$\begin{array}{c}\text { Polyspermic } \\
\text { eggs }(\%)\end{array}$} & \multirow{3}{*}{$\begin{array}{c}\text { No. of pronuclei/ } \\
\text { polyspermic egg } \\
\text { (range) }\end{array}$} \\
\hline \multicolumn{2}{|c|}{ Genotype } & \multirow{2}{*}{$\begin{array}{l}\text { No. of } \\
\text { ova } \\
\text { tested }\end{array}$} & \multirow{2}{*}{$\begin{array}{c}\text { At } \\
\text { anaphase }\end{array}$} & \multirow{2}{*}{$\begin{array}{l}\text { With } \\
\text { 2nd polar } \\
\text { body }\end{array}$} & \multirow{2}{*}{$\begin{array}{c}\text { With } \\
\text { pronuclei }\end{array}$} & & & \\
\hline Ova & Spermatozoa & & & & & & & \\
\hline$F_{1}$ & $F_{1}$ & 114 & - & - & 114 & 100 & $54 \cdot 3$ & $3 \cdot 4(3-6)$ \\
\hline CBA & CBA & 141 & - & - & 141 & $100^{*}$ & $41 \cdot 8$ & $3 \cdot 6(3-7)$ \\
\hline C57 & C57 & 120 & - & - & 118 & $98 \cdot 3$ & $3 \cdot 4$ & $3 \cdot 0-$ \\
\hline $\mathbf{K P}$ & $\mathbf{K P}$ & 112 & 2 & 4 & 103 & $97 \cdot 3$ & $2 \cdot 7$ & $3 \cdot 0-$ \\
\hline KE & $\mathbf{K E}$ & 127 & - & 1 & 119 & $94 \cdot 5^{*}$ & $2 \cdot 5$ & $3.0-$ \\
\hline CBA & C57 & 153 & 一 & 1 & 151 & $99 \cdot 3$ & $4 \cdot 6$ & $3.0-$ \\
\hline C57 & CBA & 144 & - & - & 144 & 100 & $58 \cdot 3$ & $3 \cdot 8(3-7)$ \\
\hline Outbred & $F_{1}$ & 155 & 1 & 1 & 152 & $99 \cdot 3$ & $7 \cdot 8$ & $3 \cdot 2(3-5)$ \\
\hline Outbred & CBA & 132 & - & 1 & 128 & $97 \cdot 7$ & $18 \cdot 6$ & $3 \cdot 2(3-4)$ \\
\hline Outbred & C57 & 125 & - & 2 & 116 & $94 \cdot 4$ & 3.4 & $3.0-$ \\
\hline
\end{tabular}

$F_{1}=\mathrm{CBA} \times \mathbf{C} 57$.

* Significantly different, $P<0.02$.

Series II: \% and rate of fertilization of denuded ova in vitro

In all the experimental groups, very high (up to $100 \%$ ) and similar percentages of fertilization were obtained (Table 2, Text-fig. 1).

The rate of fertilization was much faster than in Series I, and varied little. Nearly all ova contained pronuclei. Only the KP strain showed a tendency to slower fertilization (in comparison with the CBA strain, $P<0.025$ ).

The occurrence of polyspermy was very variable, but much higher than in Series $I$, and was related to the genotype of both gametes. The CBA spermatozoa gave high indices of polyspermy, dependent on the genotype of the ova (C57, CBA and outbred: $\mathrm{R} \times 2, P<0.005$ ). However, the C57 spermatozoa, which in Series I always had a low percentage and rate of fertilization, regardless of the genotype of ova (outbred, C57 or CBA), gave low and similar percentages of polyspermy.

Outbred ova which were tested with $\mathrm{F}_{1}, \mathrm{CBA}$ and C57 spermatozoa showed generally low percentages of polyspermy depending on the genotype of the male gametes $(\mathrm{R} \times 2, P<0.005)$.

\section{Abnormalities of fertilization in vitro}

In the culture medium employed, fertilization appeared normal and the stages were comparable with those observed after fertilization in vivo. In Series I only 12 of 5497 ova were activated; and in 


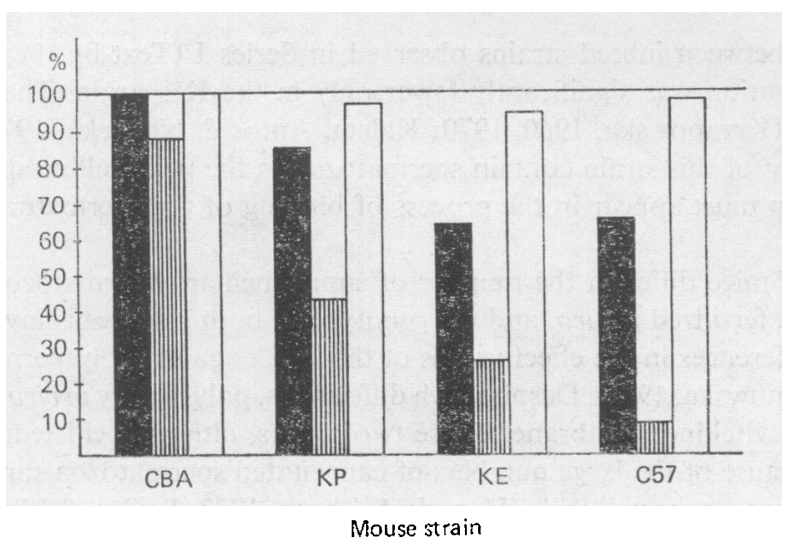

Text-fig. 1. Comparison of the effectiveness of fertilization in vivo and in vitro of inbred strains of mice. Solid columns, in vivo (CBA, KE and C57 strains: Kaleta, Antos \& Nowicka, 1976; KP strain, Krzanowska, 1960); hatched columns, in vitro, eggs with zona pellucida; open columns, in vitro, eggs without zona pellucida.

Series II, only 3 of 1326 ova were activated. In all cases, activation consisted of extrusion of the second polar body without penetration of a spermatozoon into the oocyte cytoplasm. Moreover, 8 of 2721 fertilized ova in Series I showed abnormal extrusion of the second polar body: instead of a single second polar body, two bodies separated from the cytoplasm, and the cytoplasm of the ova contained only the head of the spermatozoon, or an already formed male pronucleus. Female pronuclei were present in both polar bodies.

\section{Discussion}

In this study gametes of $F_{1}$ hybrid mice gave high percentages of fertilization comparable with the results of other authors (Toyoda, Yokoyama \& Hosi, 1971; Hoppe \& Pitts, 1973; Miyamoto \& Chang, 1973; Hoppe \& Whitten, 1974). Fertilization ran a normal course, abnormalities and spontaneous activations occurring only sporadically. Thus the method used seems to be adequate for the analysis of genetic differences in the effectiveness of fertilization. The results with intact ova confirmed the data obtained with material of the same genotype in vivo (Krzanowska, 1960, 1964, 1970; Kaleta, Antos \& Nowicka, 1976), indicating that spermatozoa from different inbred strains exhibit different abilities to penetrate ova, and that the effectiveness of fertilization depends on the genotypes of both gametes. The relationships appeared very clearly in vitro, although the effectiveness of fertilization was generally lower.

Indices of fertilization in vitro were high only for those genotypes which attain $100 \%$ fertilization in vivo ( $\mathrm{F}_{1}$ hybrids and the CBA strain). Mice of the KP, and especially of the $\mathrm{C} 57$ and $\mathrm{KE}$ strains, have a low percentage and rate of fertilization in vivo (Text-fig. 1). However, when gametes of other strains are used (e.g. CBA strain: Krzanowska, 1970; $F_{1}$ : Kaleta, Antos \& Nowicka, 1976) those of the KP, C57 and KE strains are capable of normal fertilization in vivo and an improved, but still low, rate in vitro. Tests of C57, KE and KP gametes with $F_{1}$ gametes showed that the ova and spermatozoa were responsible for the fertilization inefficiency, suggesting a common genetic control of the quality of ova and spermatozoa. The present results do, however, indicate that the rate of fertilization in vitro depends mostly on the genotype of spermatozoa.

The experiments of Series II with denuded ova were performed to test the assumption that the low percentages of fertilization in inbred strains were mainly due to disturbances of sperm capacitation or binding of spermatozoa with the receptors on the zona pellucida. Our results confirm those of Pavlok \& McLaren (1972) that the completion of sperm capacitation is not necessary for penetration of ova deprived of the zona pellucida. In Series II very high percentages of fertilization were obtained 
and the differences between inbred strains observed in Series I (Text-fig. 1) were abolished. The percentage of fertilization was significantly lower only in the KE strain. These data corroborate observations in vivo (Krzanowska, 1960, 1970; Kaleta, Antos \& Nowicka, 1976), which show that many unfertilized ova of this strain contain spermatozoa in the perivitelline space. Thus some disorders of fertilization must appear in the process of binding of the spermatozoa with the vitelline membrane.

Inbred strains of mice differ in the number of supplementary spermatozoa reaching the perivitelline space of ova fertilized in vivo, and the genotype of both gametes is involved (Krzanowska, 1970), suggesting differences in the effectiveness of the block against polyspermy at the level of the zona pellucida (Krzanowska, 1972). Despite such differences, polyspermy in vivo is rare, indicating an efficient block at the vitelline membrane. These two blocks, although efficient in vivo, become inadequate in vitro because of the large numbers of capacitated spermatozoa surrounding the ovum, especially those without a zona pellucida (Hanada \& Chang, 1972; Pavlok \& McLaren, 1972).

In the present experiments the incidence of supplementary spermatozoa was tested only in the outbred ova fertilized with CBA or KE spermatozoa. Higher numbers of outbred $\times \mathrm{KE}$ gametes confirm the differences obtained in vivo (Krzanowska, 1970).

In both series polyspermy was clearly influenced by the genotype of both gametes. In Series II there were differences in the index of polyspermy according to the genotype of the ova, suggesting differences in the effectiveness of the block at the vitelline membrane. Since outbred, C57 and KE ova fertilized in vivo of ten contain supplementary spermatozoa under the zona pellucida but do not develop polyspermy, a rapid and effective block on the vitelline membrane of these ova was to be expected. This was fully confirmed in vitro only for outbred ova, which showed little polyspermy in Series II even with very active $F_{1}$ and CBA spermatozoa. However, when C57 ova were fertilized with CBA spermatozoa, the block proved inadequate.

Ova of the CBA strain exhibit a low incidence of supplementary spermatozoa in vivo and it was expected that the block at the vitelline membrane would be less effective. When CBA spermatozoa were used in Series II, the percentage of polyspermy was much higher in CBA ova than in outbred ova and the low indices obtained when CBA ova were fertilized with C57 spermatozoa can be attributed to low fertilizing capacity of these spermatozoa.

This work was supported by the Polish Academy of Sciences within the project 09.3.1. I thank Dr Halina Krzanowska for critical review and discussion of the manuscript.

\section{References}

BRADEN, A.W.H. (1958) Variations between strains of mice in phenomena associated with sperm penetration and fertilization. J. Genet. 56, 37-47.

Hanada, A. \& Chang, M.C. (1972) Penetration of zona-free eggs by spermatozoa of different species. Biol. Reprod. 6, 300-309.

Hoppe, P.C. \& PITTS, S. (1973) Fertilization in vitro and development of mouse ova. Biol. Reprod. 8, 420 426.

Hoppe, P.C. \& WhITTEN, W.K. (1974) Maturation of mouse sperm in vitro. J. exp. Zool. 188, 133-136.

Iwamatsu, T. \& Chang, M.C. (1971) Factors involved in the fertilization of mouse eggs in vitro. J. Reprod. Fert. 26, 197-208.

Kaleta, E., Antos, K. \& Nowicka, L. (1976) Indices of in vivo fertilization in inbred strains of mice and $\mathrm{F}_{1}$ hybrids. Zwierzeta Laboratoryjne 13, 3-18.

KrzanowsKa, H. (1960) Studies on heterosis. II. Fertilization rate in inbred lines of mice and their crosses. Folia biol., Krakow 8, 269-279.
KrzanowsKa, H. (1964) Time interval between copulation and fertilization in inbred lines of mice and their crosses. Folia biol., Kraków 12, 231-244.

KrzanowsKa, H. (1965) New inbred strains of mice. Mouse News Letter 32, 54-56.

KRZANowsKa, H. (1970) Relation between fertilization rate and penetration of eggs by supplementary spermatozoa in different mouse strains and crosses. J. Reprod. Fert. 22, 199-204.

KRZANOWSKA, H. (1972) Rapidity of removal in vitro of the cumulus oophorus and the zona pellucida in different strains of mice. J. Reprod. Fert. 31, 7-14.

McLaren, A. \& Bowman, P. (1973) Genetic effects on the timing of early development in the mouse. $J$. Embryol. exp. Morph. 30, 491-498.

Mryamoto, H. \& Chang, M.C. (1973) The importance of serum albumin and metabolic intermediates for capacitation of spermatozoa and fertilization of mouse eggs in vitro. J. Reprod. Fert. 32, 193-205.

Nicol, A. \& McLaren, A. (1974) An effect of the female 
genotype on sperm transport in mice. $J$. Reprod. Fert. 39, 421-424.

Paviok, A. (1971) Study of some genetic factors participating in the fertilization of superovulated mouse ova. Folia biol. Praha 17, 50-53.

Paviok, A. \& MCLAREN, A. (1972) The role of cumulus cells and the zona pellucida in fertilization of mouse eggs in vitro. J. Reprod. Fert. 29, 91-97.
SNedrcor, G.W. (1955) Statistical Methods. Iowa State College Press, Ames, Iowa.

ToYoda, Y., Yokoyama, M. \& Hosi, T. (1971) Studies on the fertilization of mouse eggs in vitro. I. In vitro fertilization of eggs by fresh epididymal sperm. Jap. J. Anim. Reprod. 16, 147-151.

Received 26 January 1977 